\title{
DOSES E FONTES DE FÓSFORO SOBRE O COMPORTAMENTO DE PLANTAS DE TRIGO SARRACENO
}

\section{Érica de Oliveira Araújo ${ }^{1}$, Jéssica Schiochet ${ }^{2}$, Caiqui Raoni Gomes Ferreira ${ }^{3}$; Wilk Sampaio de Almeida ${ }^{4}$}

${ }^{1}$ Profa. Doutora do Departamento de Agropecuária do Instituto Federal de Educação, Ciência e Tecnologia do Amazonas, campus de Humaitá, Humaitá - AM, Brasil.

Email:ericabb25@hotmail.com

2Discente do Curso de Engenharia Agronômica do Instituto Federal de Educação,

Ciência e Tecnologia de Rondônia, campus de Colorado do Oeste, Colorado do

Oeste - RO, Brasil.

${ }^{3}$ Discente do Curso de Engenharia Agronômica do Instituto Federal de Educação,

Ciência e Tecnologia de Rondônia, campus de Colorado do Oeste, Colorado do

Oeste - RO, Brasil.

${ }^{4}$ Prof. Mestre do Departamento de Agronomia do Instituto Federal de Educação, Ciência e Tecnologia de Rondônia, campus de Colorado do Oeste, Colorado do Oeste - RO, Brasil.

Recebido em: 06/04/2018 - Aprovado em: 10/06/2018 - Publicado em: 20/06/2018 DOI: 10.18677/EnciBio_2018A38

\begin{abstract}
RESUMO
O trigo sarraceno (Fagopyrum esculentum Moench), também conhecido por trigo mourisco tem se destacado como opção de cobertura do solo, pois é uma planta capaz de extrair fósforo - $\mathrm{P}$ a partir de fosfatos minerais insolúveis em água e em ácidos fracos, através de mecanismos que promovem a formação de humo fosfatos assimiláveis pela cultura. Diante do exposto, objetivou-se com o presente trabalho avaliar o crescimento, o acúmulo de nutrientes, a eficiência de absorção e utilização de fósforo por plantas de trigo sarraceno em resposta a diferentes doses e fontes de $\mathrm{P}$ solúvel. $\mathrm{O}$ experimento foi realizado em ambiente protegido no município de Colorado do Oeste, RO. O delineamento experimental utilizado foi o de blocos casualizados, em esquema fatorial $5 \times 2$, sendo, cinco doses de fósforo $(0,40,80$, 120 e $160 \mathrm{~kg} \mathrm{ha}^{-1}$ de $\mathrm{P}_{2} \mathrm{O}_{5}$ ) e duas fontes de $\mathrm{P}$ (superfosfato simples - $21 \% \mathrm{P}_{2} \mathrm{O}_{5}$ e o superfosfato triplo - $41 \% \mathrm{P}_{2} \mathrm{O}_{5}$ ). $\mathrm{O}$ incremento nas doses de $\mathrm{P}$ solúvel aumentou $\mathrm{O}$ teor e o conteúdo de $\mathrm{P}$ nos tecidos de plantas de trigo sarraceno. A espécie vegetal de trigo sarraceno impõe potencial à extração de $\mathrm{P}$ do solo, podendo destacar-se como planta de cobertura por esta característica. Não houve efeito das diferentes fontes de fósforo sobre nenhuma das variáveis estudadas.
\end{abstract}

PALAVRAS-CHAVE: Adubo verde, cobertura do solo, Fagopyrum esculentum, mourisco 


\title{
RATES AND SOURCES OF PHOSPHORUS ON PLANT BEHAVIOR OF BUCKWHEAT
}

\begin{abstract}
The buckwheat (Fagopyrum esculentum Moench), also known as buckwheat have excelled with choice of ground cover, as it is a plant able to extract $P$ from mineral water and insoluble phosphates in weak acids, through mechanisms that promote the formation of humofosfatos culture-like. On the above, the present study aimed to evaluate the growth, the accumulation of nutrients, absorption and use efficiency of phosphorus by plants of buckwheat in response to different doses and soluble $P$ sources from soils of the Amazon West. The experiment was carried out in protected environment of the Colorado do Oeste municipally, Rondônia State, Brazil. The experimental design used was the blocks randomized design in factorial scheme $5 \times 2$, and five rates $\left(0,40,80,120\right.$ and $160 \mathrm{~kg} \mathrm{ha}^{-1}$ de $\left.\mathrm{P}_{2} \mathrm{O}_{5}\right)$ and two sources of $\mathrm{P}$ (SFS $\left(21 \% \mathrm{P}_{2} \mathrm{O}_{5}\right)$ e o SFT $\left.\left(41 \% \mathrm{P}_{2} \mathrm{O}_{5}\right)\right)$. The results conclude that the increase in doses of soluble $\mathrm{P}$ increased the level and content of $\mathrm{P}$ in the tissues of buckwheat plants; and that the species of buckwheat impose potential soil $P$ extraction and may stands out as important species. There was no effect of different phosphorus sources on any of the variables studied.
\end{abstract}

KEYWORDS: Fagopyrum esculentum Moench, buckwheat, green, compost, soil cover

\section{INTRODUÇÃO}

O trigo sarraceno (Fagopyrum esculentum Moench), também conhecido por trigo mourisco, é uma dicotiledônea pertencente à família Polygonaceae, sem nenhum parentesco com o trigo comum. É originado das regiões centrais da Ásia e cultivado em área aproximada de 3,7 milhões de hectares ano ${ }^{-1}$, sendo a China, Rússia, Ucrânia e Cazaquistão, os maiores produtores mundiais (FAO, 2016). Foi introduzido no Brasil no século $X X$, na região sul, trazido por imigrantes poloneses, russos e alemães (PACE, 1964). Os primeiros dados estatísticos da produção de mourisco no Brasil referem-se ao triênio de 1928 a 1930, quando a produção média foi de 4.500 toneladas. A produtividade brasileira atual é de aproximadamente 2500 $\mathrm{kg} \mathrm{ha}^{-1}$ (LIM, 2013).

Atualmente, essa cultura é explorada com maior intensidade, devido ao seu uso múltiplo, principalmente como planta de cobertura de solo. A cobertura do solo é uma prática de conservação do solo conhecida desde milhares de anos. O uso de plantas de cobertura em sistemas de rotação de culturas com adubação verde pode reduzir acentuadamente as perdas de solo. Isso porque a reciclagem de nutrientes confere melhor fertilidade, maior diversidade biológica, maior equilíbrio e aumento no rendimento das culturas, estabilizando a produção e possibilitando o uso racional e constante da terra, de maneira a tornar sustentável o sistema de produção (CALEGARI, 2012).

As plantas de cobertura são, de maneira geral, rústicas e agressivas. Dentre as espécies que podem ser utilizadas como planta de cobertura está o trigo mourisco ou sarraceno, caracterizado por ser uma planta rústica e de ciclo curto (6090 dias). Essa espécie destaca-se por sua eficiência no controle de plantas daninhas, tanto de espécies monocotiledôneas quanto dicotiledôneas, decorrente da 
sua utilização como cultura de cobertura, pela sua tolerância à acidez, capacidade de utilização de sais de fósforo e potássio, pouco solúvel no solo (KLEIN et al., 2010).

O trigo sarraceno destacou-se como exportador de nutrientes, com quantidades acumuladas médias de N, K, Ca, Cu e Fe em seus tecidos e produção de matéria seca $3.576 \mathrm{~kg} \mathrm{ha}^{-1}$ aos 90 dias após a emergência (Menezes e Leandro, 2004). Embora o trigo sarraceno não ter se destacado pela absorção de fósforo - $P$ no estudo de Menezes e Leandro (2004), esta planta é capaz de extrair P a partir de fosfatos minerais insolúveis em água e em ácidos fracos, através de mecanismos que promovem a formação de humo fosfatos assimiláveis pela cultura. A alta capacidade de reciclagem de $\mathrm{N}$ e $\mathrm{K}$ por esta cultura foi relatada por Klein et al. (2010), os quais estudaram cultivares precoces e tardias de trigo sarraceno. Portanto, é possível inferir que estas plantas têm a capacidade de extrair elementos menos solúveis e de mobilizar nutrientes de camadas de solo mais profundos, em função do alto crescimento do sistema radicular.

Muitos agricultores vêm utilizando o trigo mourisco como planta sucessora de culturas de grão como soja, milho e sorgo, principalmente devido à sua capacidade de se desenvolver em solos ácidos, por sua utilização como adubo verde e por sua capacidade de desenvolvimento com baixa umidade, o que a torna ideal para plantio na safrinha e rotação de cultura em áreas de cultivos extensivos (GORGEM, 2013). Além disso, o desenvolvimento de plantas de trigo sarraceno mais eficientes nutricionalmente constitui uma solução para aumento da produtividade e redução do custo de produção das culturas, pois esta planta extrai elementos menos solúveis e de mobiliza nutrientes de camadas de solo mais profundos, em função do crescimento e desenvolvimento do sistema radicular. Contudo, as informações sobre o acúmulo e a eficiência de utilização de nutrientes por essa cultura são escassas na literatura científica. Isso demonstra que muitas pesquisas, inclusive básicas, são necessárias para que se avance em tecnologias destinadas à produção agrícola. Diante do exposto, objetivou-se com o presente trabalho avaliar o crescimento, o acúmulo de nutrientes, a eficiência de absorção e utilização de fósforo por plantas de trigo sarraceno em resposta a diferentes doses e fontes de $P$ solúvel.

\section{MATERIAL E MÉTODOS}

O experimento foi desenvolvido em ambiente protegido do Setor de Produção Vegetal do Instituto Federal de Educação, Ciência e Tecnologia de Rondônia, campus Colorado do Oeste, RO, cujas coordenadas geográficas são $13^{\circ} 06^{\prime} \mathrm{S}$ e $60^{\circ}$ 29' W, com altitude média de 407 metros. O clima regional, segundo a classificação de Koppen, é do tipo Am, tropical quente e úmido com duas estações bem definidas e médias anuais, respectivamente, de temperatura e precipitação pluviométrica variando de $24^{\circ} \mathrm{C}$ a $26^{\circ} \mathrm{C}$ e de $1900 \mathrm{~mm}$ a $2200 \mathrm{~mm}$ (ALVARES et al., 2013). A amostra de terra utilizada foi coletada na camada de $0-20 \mathrm{~cm}$ de um solo com $428 \mathrm{~g}$ $\mathrm{kg}^{-1}$ de areia, $210 \mathrm{~g} \mathrm{~kg}^{-1}$ de silte e $362 \mathrm{~g} \mathrm{~kg}^{-1}$ de argila.

A análise química de terra antes da instalação do experimento resultou nos seguintes valores: M.O.: 28,90 $\mathrm{g} \mathrm{dm}^{-3} ; \mathrm{pH}\left(\mathrm{CaCl}_{2}\right): 6,1 ; \mathrm{P}: 10 \mathrm{mg} \mathrm{dm}^{-3} ; \mathrm{K}: 0,40 \mathrm{cmol}_{\mathrm{c}}$

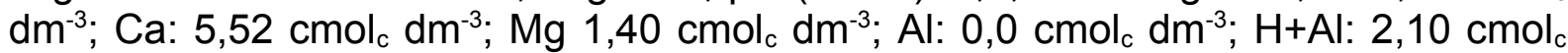
$\mathrm{dm}^{-3}$; SB: $7,32 \mathrm{cmol}_{\mathrm{c}} \mathrm{dm}^{-3}$; CTC: $9,42 \mathrm{cmol}_{\mathrm{c}} \mathrm{dm}^{-3}$, e saturação por bases $77 \%$.

$\mathrm{O}$ delineamento experimental utilizado foi o de blocos casualizados, em esquema fatorial $5 \times 2$, sendo, cinco doses de fósforo e duas fontes solúveis de $\mathrm{P}_{2} \mathrm{O}_{5}$, com quatro repetições. As doses de $P$ consistiram de 0, 40, 80, 120 e $160 \mathrm{~kg} \mathrm{ha}^{-1}$ de 
$\mathrm{P}_{2} \mathrm{O}_{5}$, aplicadas no plantio; e as fontes de $\mathrm{P}_{2} \mathrm{O}_{5}$ utilizadas foram superfosfatos simples - SFS $\left(21 \% \mathrm{P}_{2} \mathrm{O}_{5}\right)$ e o superfosfato triplo - SFT $\left(41 \% \mathrm{P}_{2} \mathrm{O}_{5}\right)$.

Com base nos resultados da análise química do solo, procedeu-se à adubação de base para garantir o estabelecimento da cultura. As doses de P foram convertidas para $\mathrm{mg} \mathrm{kg}^{-1}$ utilizando valores de densidade do solo. Os micronutrientes foram aplicados conforme a exigência da cultura.

As unidades experimentais foram compostas por vasos plásticos com capacidade de $12 \mathrm{dm}^{-3}$, preenchidos com terra seca ao ar, passada em peneira de 4 $\mathrm{mm}$ de abertura. A umidade nos vasos foi controlada diariamente, visando manter $\mathrm{o}$ solo com $60 \%$ da capacidade de campo.

As sementes foram colocadas para germinar diretamente nos vasos e, aos 10 dias após a emergência - DAE realizados os desbastes, deixando apenas uma planta em cada unidade experimental.

As avaliações foram realizadas aos 60 DAE, correspondentes ao final do ciclo da cultura. A altura das plantas foi obtida pela medição do colo da planta até o meristema apical, utilizando-se uma fita métrica; e o diâmetro do caule foi determinado com o auxílio de paquímetro digital, na altura de $2 \mathrm{~cm}$ do colo da planta. Posteriormente, as plantas foram coletadas e divididas em raiz e parte aérea. Em seguida, todo o material vegetal coletado foi lavado em água corrente e água deionizada, respectivamente.

O comprimento de raiz foi determinado com uma régua graduada e o volume de raiz pelo método da proveta, no qual as raízes foram submersas em proveta graduada com volume de água destilada conhecido, sendo o volume determinado pela diferença entre o volume inicial e final do recipiente. A massa verde das plantas foi determinada pela pesagem do material em balança de precisão. Posteriormente, as raízes e a parte aérea foram colocadas para secar em estufa a $65^{\circ} \mathrm{C}$ por 72 horas, para aferição da massa seca de raiz. Após secagem, o material vegetal foi moído (moinho tipo Wiley) e submetido à digestão nitroperclórica, para determinação dos teores de $\mathrm{P}$ nas diferentes partes da planta (raiz e parte aérea), conforme metodologia descrita em Embrapa (2009).

O índice de eficiência de absorção, razão entre o conteúdo total de nutriente na planta e a massa seca das raízes, foi calculado de acordo com Swiader et al. (1994). Por sua vez, a eficiência de transporte, razão entre o conteúdo de nutriente na parte aérea e o conteúdo de nutriente na planta e a eficiência de utilização, razão entre a massa seca total produzida e o acúmulo total de nutriente na planta, foram calculados de acordo com Siddiqi e Glass (1981).

Para as análises de normalidade dos resíduos (SHAPIRO ; WILK, 1965) e da variância foi utilizado o programa computacional Sisvar. Os efeitos doses de $P$, dentro de cada fonte do nutriente foram avaliados pelo teste de Scott-Knott a 5\% de probabilidade. Para a variável com significância estatística em função das doses de $P$ foi utilizada análise de regressão.

\section{RESULTADOS}

Houve diferença significativa $(p \leq 0,05)$ para teor de $P$ na parte aérea e na planta, para o conteúdo de $\mathrm{P}$ na parte aérea e na planta e para a eficiência de utilização do $P$ com $o$ incremento das doses de fósforo. Enquanto que apenas 0 conteúdo de $\mathrm{P}$ na parte aérea e o conteúdo de $\mathrm{P}$ na planta responderam à interação entre doses e fontes de $\mathrm{P}$ solúvel (Tabela 1). 
TABELA 1. Valores $F$, Média e CV para altura de plantas (ALT), diâmetro do caule (DIA), volume de raiz (VR), massa seca da parte aérea (MSPA), massa seca da raiz (MSR), massa seca total (MSTO), teor de $P$ na parte aérea (TPPA), teor de $\mathrm{P}$ na raiz (TPR), teor de $\mathrm{P}$ na planta (TPPL), conteúdo de $P$ na parte aérea (CPPA), conteúdo de $P$ na raiz (CPR), conteúdo de $P$ na planta (CPPL), eficiência de absorção de $P$ (EAP), eficiência de transporte de $P(E T P)$ e eficiência de utilização do $P$ (EUP) por plantas de trigo sarraceno em resposta a doses e fonte de $\mathrm{P}$ solúvel. Colorado do Oeste, RO (2017). 


\begin{tabular}{|c|c|c|c|c|c|c|}
\hline \multirow{2}{*}{$\begin{array}{l}\text { Fonte de } \\
\text { variação }\end{array}$} & \multirow[t]{2}{*}{$\mathbf{G L}$} & \multicolumn{5}{|c|}{$\operatorname{Pr}>\mathrm{F}$} \\
\hline & & ALT & DIA & VR & MSPA & MSR \\
\hline Fonte (F) & 1 & 0,50 & 0,84 & 0,34 & 0,41 & 0,88 \\
\hline Dose (D) & 4 & 0,46 & 0,51 & 0,47 & 0,81 & 0,70 \\
\hline$F \times D$ & 4 & 0,71 & 0,76 & 0,74 & 0,32 & 0,40 \\
\hline Resíduo & 30 & & & & & \\
\hline Média & & 146 & 9,13 & 34,07 & 34,23 & 4,31 \\
\hline CV (\%) & & 10,30 & 10,89 & 17,04 & 13,30 & 10,69 \\
\hline \multirow[t]{2}{*}{$\begin{array}{l}\text { Fonte de } \\
\text { variação }\end{array}$} & $\mathbf{G L}$ & \multicolumn{5}{|c|}{$\operatorname{Pr}>\mathrm{F}$} \\
\hline & & MSTO & TPPA & TPR & TPPL & CPPA \\
\hline Fonte (F) & 1 & 0,45 & 0,62 & 0,20 & 0,71 & 0,69 \\
\hline Dose (D) & 4 & 0,84 & $0,00^{*}$ & 0,18 & $0,00^{*}$ & $0,00^{*}$ \\
\hline$F \times D$ & 4 & 0,20 & 0,12 & 0,08 & 0,53 & $0,04^{*}$ \\
\hline Resíduo & 30 & & & & & \\
\hline Média & & 38,55 & 2,64 & 1,88 & 4,53 & 90,50 \\
\hline CV (\%) & & 13,68 & 14,71 & 13,41 & 7,81 & 18,28 \\
\hline \multirow[t]{2}{*}{$\begin{array}{l}\text { Fonte de } \\
\text { variação }\end{array}$} & $\mathbf{G L}$ & \multicolumn{5}{|c|}{$\operatorname{Pr}>\mathrm{F}$} \\
\hline & & $\begin{array}{l}\text { CPR } \\
\end{array}$ & CPPL & EAP & ETP & EUP \\
\hline Fonte (F) & 1 & 0,42 & 0,60 & 0,64 & 0,58 & 0,76 \\
\hline Dose (D) & 4 & 0,33 & $0,00^{*}$ & 0,27 & 0,44 & $0,00^{*}$ \\
\hline$F \times D$ & 4 & 0,28 & $0,03^{*}$ & 0,88 & 0,40 & 0,33 \\
\hline Resíduo & 30 & & & & & \\
\hline Média & & 8,06 & 98,57 & 25,71 & 91,69 & 15,49 \\
\hline CV (\%) & & 17,97 & 17,40 & 22,29 & 3,46 & 18,70 \\
\hline
\end{tabular}

*significativo pelo teste de Scott Knott a 5\% de probabilidade. CV - coeficiente de variação.

O trigo sarraceno destacou-se como um material exportador de fósforo, uma vez que, apresentou as maiores quantidades acumuladas de $\mathrm{P}$ em seus tecidos, potencializando uma importante espécie de cobertura na remoção de $P$ do solo (Figura 1). As plantas de cobertura têm a capacidade de extrair elementos menos solúveis e de mobilizar nutrientes de camadas de solo mais profundas, em função do alto crescimento do sistema radicular e pelo fato desse sistema, em fabáceas, alcançar grandes profundidades. Ainda que a produção de massa seca não tenha sido significativa, o potencial dessas espécies em fornecer nutrientes às culturas subsequentes pode ser constatado por meio dos teores de $\mathrm{P}$. 


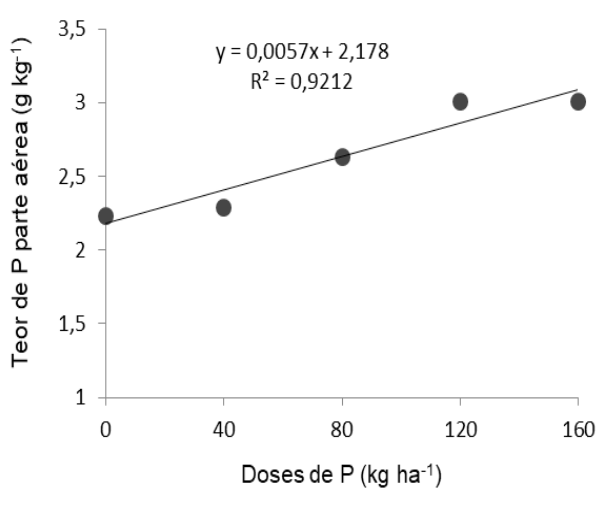

A
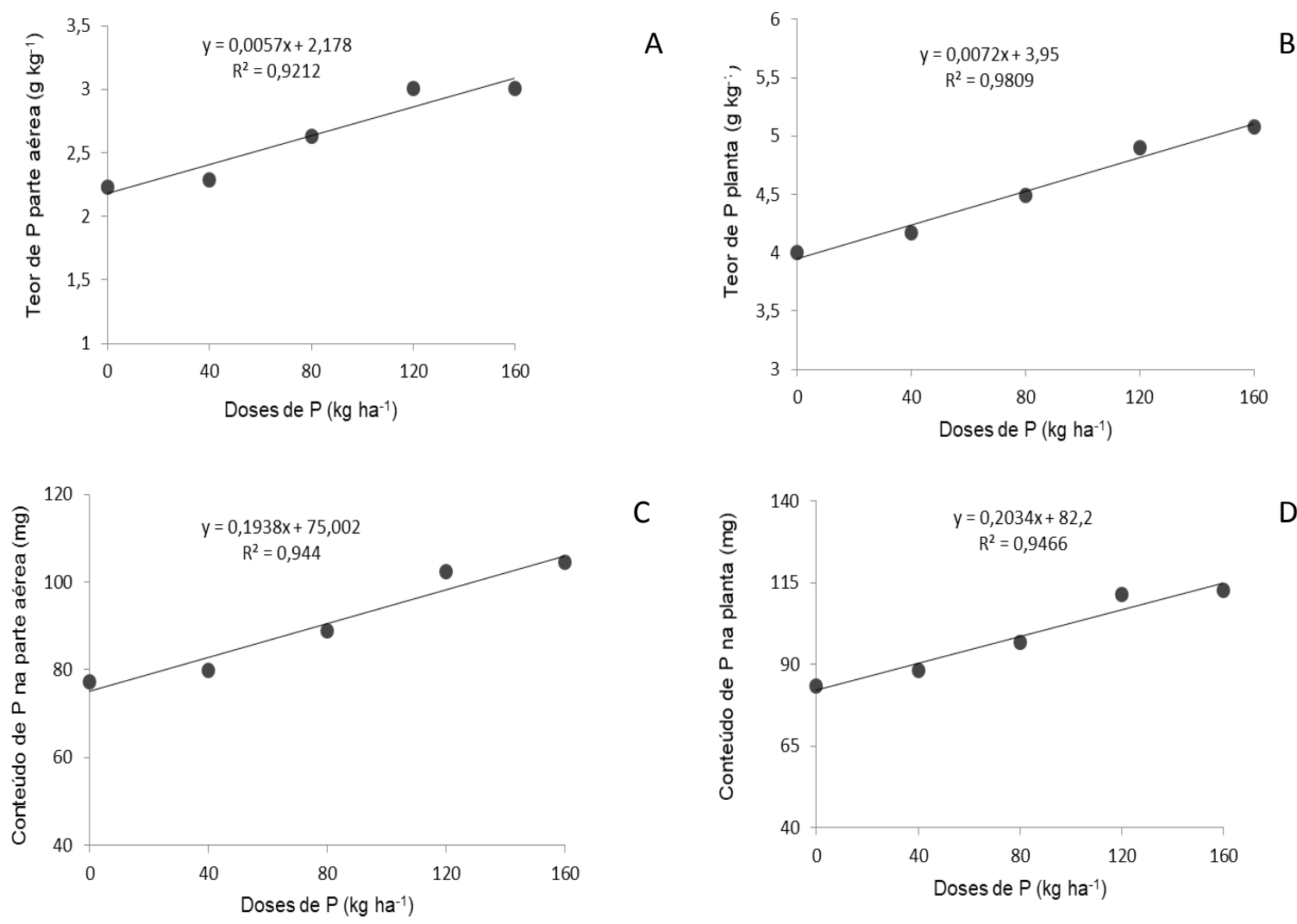

FIGURA 1. Teor de $P$ na parte aérea $(A)$, teor de $P$ na planta $(B)$, conteúdo de $P$ na parte aérea $(A)$, e conteúdo de $P$ na planta $(B)$ de trigo sarraceno em resposta a diferentes doses P. Colorado do Oeste, RO (2017).

$O$ conteúdo de $P$ na parte área e na planta foi influenciado significativamente $(p \leq 0,05)$ pelas doses e fontes fósforo no solo (Figura 2A e 2B). Quanto mais fósforo disponível no solo maior será o gradiente de concentração deste elemento, ocasionando, portanto, aumento no acúmulo de $\mathrm{P}$ na parte aérea e incorporação desse nutriente na biomassa.
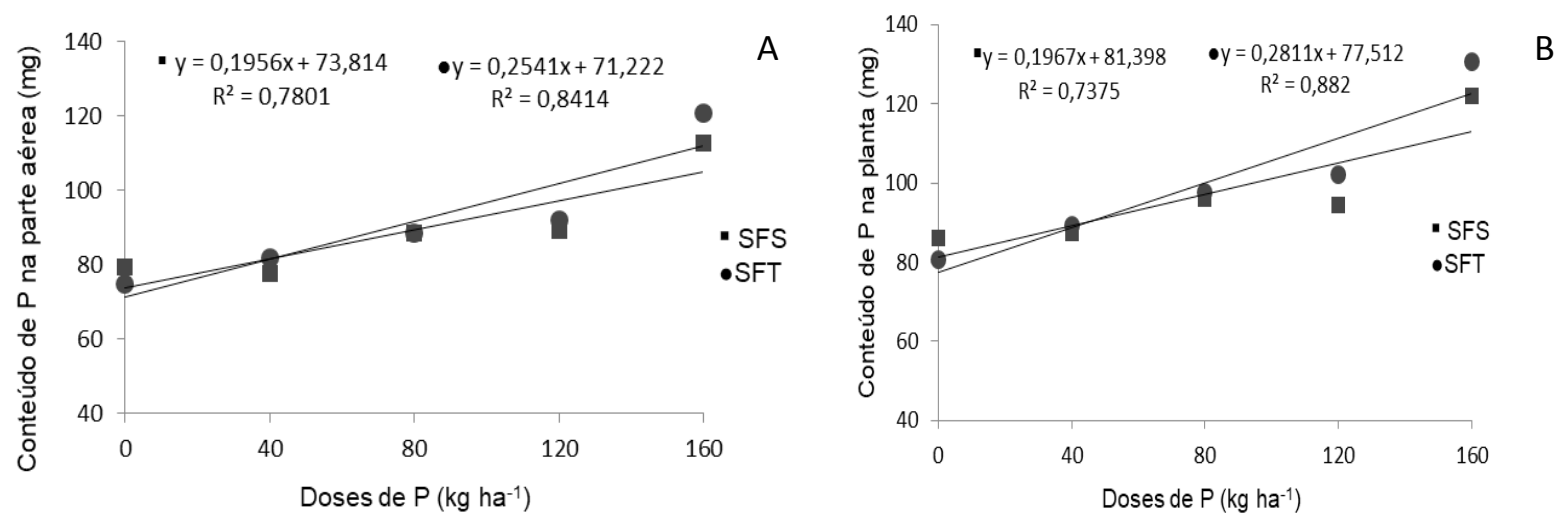

FIGURA 2. Conteúdo de $P$ na parte aérea $(A)$ e conteúdo de $P$ na planta $(B)$ de trigo sarraceno em resposta a diferentes doses e fontes de $\mathrm{P}$ solúvel. Colorado do Oeste, RO (2017). 
A eficiência de utilização do $P$ correlaciona-se negativamente ao incremento das doses de fósforo (Figura 3). A utilização de P por plantas de trigo sarraceno foi superior na dose de $40 \mathrm{~kg} \mathrm{ha}^{-1}$ de $\mathrm{P}$, reduzindo com o aumento das doses do nutriente no solo. À medida que se ultrapassa a capacidade da planta em absorver o nutriente para produção, o $\mathrm{P}$ pode ser lixiviado ou acumular-se nos tecidos, reduzindo sua eficiência de aproveitamento.

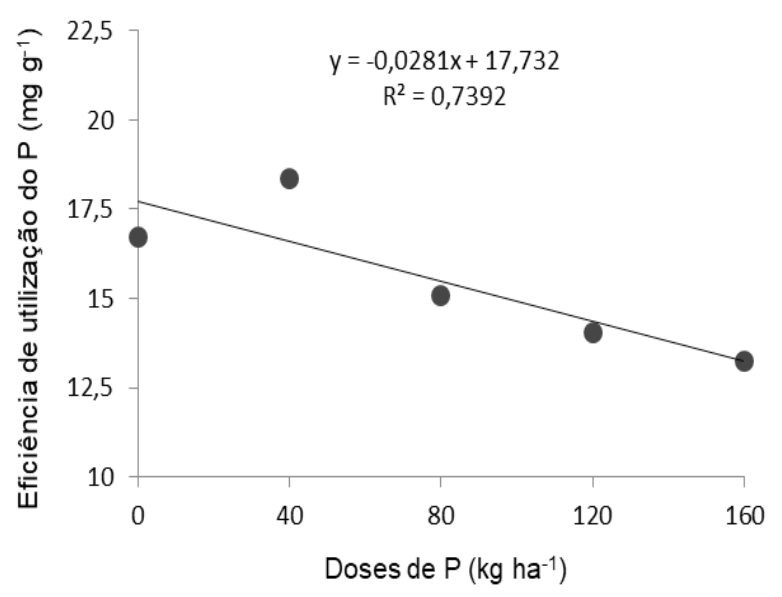

FIGURA 3. Eficiência de utilização do $P$ por plantas de trigo sarraceno em resposta a diferentes doses de P. Colorado do Oeste, RO (2017).

\section{CONCLUSÃO}

O incremento nas doses de $\mathrm{P}$ solúvel aumentou o teor e o conteúdo de $\mathrm{P}$ nos tecidos de plantas de trigo sarraceno.

A espécie vegetal de trigo sarraceno impõe potencial à extração de $\mathrm{P}$ do solo, podendo destacar-se como importante espécie de cobertura.

Não houve efeito das diferentes fontes de fósforo sobre nenhuma das variáveis estudadas.

\section{AGRADECIMENTOS}

Os autores agradecem ao Instituto Federal de Educação, Ciência e Tecnologia de Rondônia, Campus Colorado do Oeste pela institucionalização e disponibilização de recursos para realização desta pesquisa.

\section{REFERÊNCIAS}

ALVARES, C.A.; STAPE, J.L.; SENTELHAS, P.C.; GONÇALVES, J.L.M.; SPAROVEK, G. Köppen's climate classification map for Brazil. Meteorologische Zeitschrift, v.22, p.711-728, 2013.

CALEGARI, A. Plantas de cobertura em sistema Plantio Direto de Qualidade (SPDq). Revista A Granja, Porto Alegre, RS: Centaurus, v.68, n.763, p 67-69, 2012. 
EMPRESA BRASILEIRA DE PESQUISA AGROPECUARIA - EMBRAPA. Manual de análises químicas de solos, plantas e fertilizantes.- 2. Ed, Brasília., Embrapa Informação Tecnológica, 2009. 627 p.

FAO, FAO Statistical Yearbook (2016). FAO Statistics Division. Disponível em: $<$ www.faostat.fao.org>. Acessado em 10/09/2016.

GORGEN, A.V. Produtividade e qualidade da forragem de milheto (Pennisetum glaucum e de trigo mourisco (Fagopyrum esculentum Moench) cultivado no cerrado. Brasília: Faculdade de Agronomia e Medicina Veterinária, 49 páginas. Monografia. Universidade de Brasília, 2013. Disponível em: < http://bdm.unb.br/bitstream/10483/4733/6/2013_AngelaValentiniGorgen.pdf>

KLEIN, V.A.; NAVARINI, L.L.; BASEGGIO, M.; MADALOSSO, T.; COSTA, L.O. Trigo mourisco: uma planta de triplo propósito e uma opção para rotação de culturas em áreas sob plantio direto. Revista Plantio Direto, 117.ed., 2010. Disponível em: <http://www.plantiodireto.com.br/?body=cont_int\&id=991>

MENEZES, L.A.S; LEANDRO, W.M. Avaliação de espécies de coberturas do solo com potencial de uso em sistemas de plantio direto. Pesquisa Agropecuária Tropical, v.34.p.173-180. 2004.

PACE, T. Cultura do trigo sarraceno: história, botânica e econômica. Rio de Janeiro: Ministério da Agricultura, Serviço de informação Agrícola, 71p, 1964.

SHAPIRO, S.S.; WILK, M.B. An analysis of variance test for normality (complete samples). Biometrika 52, 591-611, 1965.

SIDDIQI, M. Y.; GLASS, A. D. M. Utilization index: a modified approach to the estimation and comparison of nutrient utilization efficiency in plants. Journal of Plant Nutrition, v. 4, n.3, p. 289-302, 1981.Disponível em: < https://doi.org/10.1080/01904168109362919>

SWIADER, J. M. CHYAN, Y.; FREIJI, F. G. Genotypic differences in nitrate uptake and utilization efficiency in pumpkin hybrids.Journal of Plant Nutrition, v.17, n.10, p.1687-1699, 1994. Disponível em: < https://doi.org/10.1080/01904169409364840> 